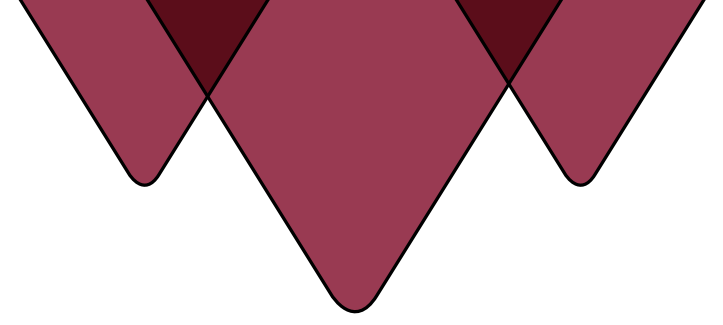

\title{
Research and Indigenous Librarianship in Canada
}

\author{
Deborah Lee \\ University of Saskatchewan
}

\begin{abstract}
This thought piece provides essential information about ethical research practices related to research involving Indigenous peoples so that academic librarians (both Indigenous and non-Indigenous) are better informed about the complex issues that exist and arise in such endeavours. Woven throughout the paper are guidance and strategies to avoid causing harm when doing research with Indigenous peoples and communities, such as misrepresenting Indigenous peoples, cultures, and epistemologies. A brief account of the legacy of a long history of unethical research practices conducted by Western researchers who extracted Indigenous knowledge speaks to why Indigenous peoples do not trust academic research projects. Researchers need to question their own motives when they consider conducting research with Indigenous peoples and to respect that we want to be involved in our own solutions and in research that utilizes Indigenous values, with the goal that "nothing [is done] about us without us." Key to building relationships and finding success in the research undertaken are an in-depth understanding of Indigenous protocols, values, and ways of knowing, as well as evidence of the researcher making a long-term commitment to the research and the community. Further, such an understanding provides an access point for librarians to contribute to the decolonization of library services while supporting Indigenous researchers.
\end{abstract}

Keywords: Indigenous librarianship · Indigenous protocols · Indigenous research methodologies

\section{RÉSUMÉ}

Cet article de réflexion fournit des renseignements essentiels sur les pratiques de recherche éthiques auprès des peuples autochtones afin que les bibliothécaires universitaires (autochtones et non autochtones) comprennent mieux les questions complexes existantes et celles qui surviennent dans le cadre de ces projets. L'article regroupe des conseils et des stratégies pour éviter de nuire dans le cadre de la recherche avec les peuples et les communautés autochtones, par exemple en représentant faussement les peuples, les cultures et les épistémologies autochtones. Un bref compte rendu de l'héritage d'une longue histoire de pratiques de recherche contraires à l'éthique menées par des chercheurs occidentaux qui ont extrait des connaissances autochtones explique pourquoi les peuples autochtones ne font pas confiance aux projets de recherche universitaire. Les chercheurs doivent s'interroger sur leurs propres motivations lorsqu'ils envisagent de mener des recherches avec les 
peuples autochtones et respecter le fait que nous voulons participer à nos propres solutions et à des recherches qui utilisent les valeurs autochtones, dans le but que "rien [ne soit fait] à notre sujet sans nous". La clé de l'établissement de relations et du succès de la recherche entreprise est une compréhension approfondie des protocoles, des valeurs et des façons de savoir autochtones, ainsi que la preuve que le chercheur s'engage à long terme. De plus, cette compréhension permet aux bibliothécaires de contribuer à la décolonisation des services de bibliothèque tout en appuyant les chercheurs autochtones.

Mots-clés: bibliothéconomie autochtones - protocoles autochtones · méthodologies de recherche autochtones

$\mathbf{I}$ $\mathrm{N}$ this paper, I discuss opportunities, challenges, and concerns related to the research process as it pertains to Indigenous librarianship in Canada. For readers who are unfamiliar with what constitutes Indigenous librarianship, a brief definition is:

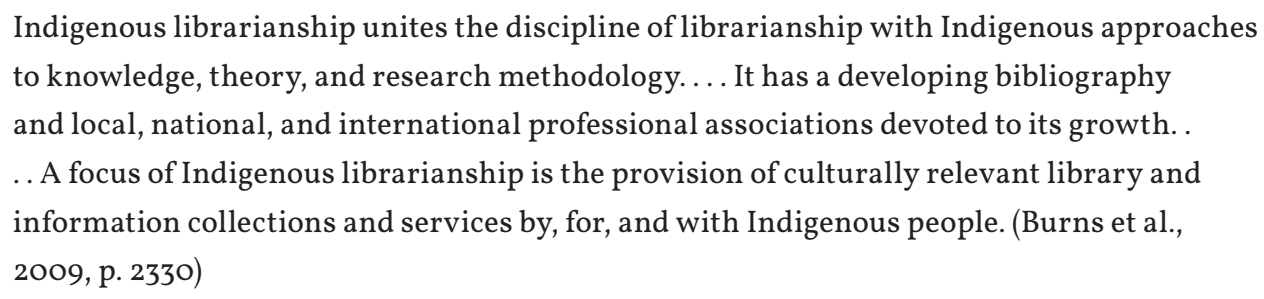

For clarification, Indigenous librarianship, according to the above definition, includes work done by both Indigenous and non-Indigenous librarians to support Indigenous researchers. And, while Indigenous librarians working in the academy are rare, our numbers are slowly growing from the twelve who were interviewed across Canada in 20I4, which included six working in tribal college libraries (Lee, 20I7). This growth in numbers of Indigenous academic librarians in Canada (for a total of I9) was confirmed in the most recent Canadian Association of Professional Academic Librarians (CAPAL) census publication (CAPAL, et al., 2019, 63) and hopefully more of us will join the academy within the next few years. In this paper, however, I provide guidance for all practicing and aspiring academic librarians because it is important to be culturally competent in serving Indigenous researchers in any capacity (e.g., working at the reference desk, teaching information literacy skills, developing and managing collections, cataloguing and providing metadata services, doing web design, and conducting research).

This paper is also timely in that there is a push to decolonize and Indigenize academic institutions (including libraries) across the country as a response to the 94 Calls to Action from Canada's Truth and Reconciliation Commission. One current movement towards decolonization in libraries concerns the work being done to 
"decolonize description" (this term is thought to have been coined by the University of Alberta's Decolonizing Description Working Group) and "fix" the outdated and offensive terminology of Library of Congress Subject Headings used to describe Indigenous library materials. More than grumblings by Indigenous librarians in their workplaces (particularly in relation to teaching offensive terminology, such as "Indians of North America," during information literacy instruction sessions), this movement is now a "thing." This is evidenced by the purpose and content of three recent gatherings: the Making Meaning Symposium, which took place at the University of Alberta in February 2018; the In Our Own Words gathering held at Ryerson University in partnership with York University in June 2018; and the Sorting Libraries Out symposium hosted by Simon Fraser University (downtown campus) in partnership with the University of British Columbia in March 2019. All three gatherings helped to develop a community of practice across the country to work through the complexities of a unified way to deal with the American subject headings that are so problematic for describing Indigenous materials in Canada. Other recent publications also speak to this phenomenon (Farnel et al., 20I8; Bone \& Lougheed, 2018). Likewise, in this paper I propose that decolonizing academic library research practices when the research involves Indigenous peoples will also create better understanding between Indigenous and non-Indigenous peoples. In order to do so, I will explore differences between Western and Indigenous research methodologies, providing guidance on and examples of Indigenous research protocols. But first, it is necessary to provide some background and context on research involving Indigenous peoples.

\section{Background and Context}

During a conference presentation at the 2016 CAPAL conference in Calgary, Alberta, I addressed similar issues by providing an in-depth look at Indigenous research methodologies, including how they are different and why they are needed. For instance, I discussed many concepts put forward by Linda Tuhiwai Smith (Maori) in her seminal book Decolonizing Methodologies: Research and Indigenous Peoples (1999). First and foremost, it was necessary to explain that research conducted on Indigenous peoples in the igth and 2oth centuries was primarily done by non-Indigenous people with no benefits coming back from the research for the Indigenous peoples who were "being studied," not even the provision of a report on the results of the study. At the same time, benefits for the non-Indigenous researchers were huge, including obtaining academic qualifications, such as graduate degrees as well as tenure and promotion at their institutions. And, sometimes, the Indigenous knowledges that were "tapped" also made pharmaceutical companies very profitable. As Linda Smith wrote: 
Research within late-modern and late-colonial conditions continues relentlessly and brings with it a new wave of exploration, discovery, exploitation and appropriation.

Researchers enter communities with goodwill in their front pockets and patents in their back pockets. (p. 24)

Clearly, non-Indigenous researchers were not accountable to the Indigenous people who were being researched. Given the importance of the Indigenous values of relational accountability and reciprocity (which I will explore in more depth later), these unethical research practices were considered a breach of trust by Indigenous communities. Further, no care was taken to ensure the accuracy of their research findings by obtaining approval of those findings from those researched. This meant that Western researchers had ample space and voice to conclude in their research outputs whatever they wanted to in order to fit their research agendas, such as developing patents using the Indigenous knowledge that was shared with them without the communities also receiving benefit from these patents. To further elaborate on unethical research practices of Western researchers when conducting research with Indigenous peoples, I point out that the practice of sharing Indigenous knowledge that was not meant to be shared is not uncommon. Battiste and Henderson (2000) provide several examples of Western researchers' actions that generate distrust by Indigenous peoples, including

An interesting Australian court decision in this regard is Foster v. Mountford (1976), which barred the sale of a book containing sacred knowledge that had been shared by elders, in confidence, with a well-known anthropologist. (p. I4I)

Thus, there are reasons why Indigenous knowledge has been protected. Again, Battiste and Henderson provide an important teaching about how Indigenous research ethics and protocols are different from Western research ethics, as follows:

The starting point for any ethical research of Indigenous knowledge and heritage must be the law of the Indigenous people being studied, which defines what constitutes property, identifies who has the right to share knowledge and property, and determines who is to benefit from and who is to be responsible for such sharing. Indigenous peoples' knowledge and heritage are not commodities, nor are they the property of the nation-states or their researchers. Indigenous knowledge and heritage are sacred gifts and responsibilities that must be honoured and held for the benefit of future generations. (ibid., p. I44)

Additionally, a common understanding among Indigenous peoples is that we have felt "researched to death" long before the turn of the millennium (see Goodman et al., 20I8; Blair, 2015; First Nations Information Governance Centre, 2014). A consequence of this situation is that it has been far more difficult to attract Indigenous peoples as research participants in the last 40 years or so (possibly since Native Studies programs emerged in universities and Indigenous peoples in Canada have been pursuing higher education and learning about the ramifications of unethical research 
practices). Even when the researchers are Indigenous, there is often resistance by Indigenous community members to participate in research projects due to a lack of trust by Indigenous peoples and communities in the academic research process. For instance, only one of the participants in my 200 I study was a student whom I did not know in advance of the call to participate in the research project.

The Tri-Council funding agencies ${ }^{1}$ in Canada have recognized some past wrongs that have occurred involving research with Indigenous peoples and have recently committed to enforcing stringent checks and balances for any such research projects going forward. In their policy statement on the ethical conduct of research involving humans, the core principles are Respect for Persons, Concern for Welfare, and Justice, the latter of which begins with the following passage:

Justice refers to the obligation to treat people fairly and equitably. Fairness entails treating all people with equal respect and concern. Equity requires distributing the benefits and burdens of research participation in such a way that no segment of the population is unduly burdened by the harms of research or denied the benefits of the knowledge generated from it. (Panel on Research Ethics, 20I4, chap. I para. 20)

This policy document, commonly known as the TCPS 2 (formally, the Tri-Council Policy Statement, 2nd edition), includes a specific chapter (chapter 9) about implementing guidelines and monitoring research involving Indigenous peoples. I will say more on this topic later. However, I want to also acknowledge that Indigenous communities themselves may have established their own similar research restrictions. One such group is the Mi'kmaw Ethics Watch associated with the Cape Breton University. Here is some of their research ethics protocol, established in I999:
A Mi'kmaw Ethics Committee has been appointed by the Sante' Mawio'mi (Grand Council) to establish a set of principles and protocols that will protect the integrity and cultural knowledge of the Mi'kmaw people. These principles and protocols are intended to guide research and studies in a manner that will guarantee that the right of ownership rests with the various Mi'kmaw communities. These principles and protocols will guarantee only the highest standards of research. Interpretation and conclusions drawn from the research will be subject to approval to ensure accuracy and cultural sensitivity. ${ }^{2}$ (Mi'kmaw Ethics Watch, Cape Breton University, "Background," para. 3)

Thus, ethical standards and principles for conducting research with Indigenous peoples and communities serve as the core framework in the development of Indigenous research methodologies.

Since the publication of Smith's book, other Indigenous researchers, such as Jo-ann Archibald (2008), Shawn Wilson (2008), and Margaret Kovach (2009), have

I. The Tri-Council funding agencies include the Canadian Institutes of Health Research (CIHR), the Natural Sciences and Engineering Research Council of Canada (NSERC), and the Social Sciences and Humanities Research Council of Canada (SSHRC).

2. The Mi'kmaw Ethics Watch includes further information on the specific principles. 
contributed insights into specific kinds of methodologies that embody Indigenous perspectives in Canadian contexts, using methods such as storytelling, ceremony and accountability, conversation or dreams, and relational epistemologies. All of these speak to Indigenous values, the importance of Indigenous knowledges, and the necessity of centering reciprocal relationships when conducting research with Indigenous peoples. These types of approaches are more accepted by Indigenous peoples and communities, and the success of the research is often measured by the strength of the relationships developed between the researcher and the research participants. A current common mantra being used in Indigenous communities, including by Indigenous researchers, to promote this message is "nothing about us without us" (this quote is attributed to Dr. Marie Battiste, 2015).

But there has not been a canon for conducting qualitative research with Indigenous peoples in the field of library and information studies. As such, this article begins a conversation to provide some understanding of the issues and some standards for librarians that can guide the processes of conducting ethical research with Indigenous peoples and thereby avoid the controversial issue of appropriation of Indigenous voice. By this I mean that non-Indigenous librarians should consider that any research they are planning to do with Indigenous peoples should not be entered into lightly and should be done with humility (that is, an approach of being there to listen and learn and not discounting what the participant is sharing, or insisting on their own interpretation of what knowledge is). They should also consider that this research could be better done with the involvement of Indigenous library employees or librarians (harkening back to the phrase mentioned above, "nothing about us without us"). They may wish to ask themselves how they can ensure that the research will not be harmful to Indigenous peoples without the involvement of Indigenous library folks. This recommendation holds true even if the research they wish to undertake does not involve surveying or interviewing Indigenous people.

It is vitally important that academic (and other) librarians understand that Indigenous librarians exist and that our expectation is that we can and will do this research, because an in-depth understanding of Indigenous values, histories, and protocols is essential for the success of research projects involving Indigenous peoples. In Canada, it is possible that Indigenous academic librarians would consider working with non-Indigenous librarians on such projects; this could be beneficial in terms of access to other research resources (such as funding). Such an invitation would likely be extended to a non-Indigenous librarian who has demonstrated a long-term commitment to and accountability for improving library services for Indigenous peoples. However, the invitation to do this work should come from Indigenous academic librarians. By contrast, in other countries, such as Aotearoa / 
New Zealand, the chances of a partnership materializing between Indigenous and non-Indigenous librarians would be slim. As a case in point, for the 2019 International Indigenous Librarians' Forum, which was hosted in Auckland by the Maori library workers association of Aotearoa (Te Ropu Whakahau), the organizers deemed that all presenters at this conference must be Indigenous.

\section{What is Research or Scholarship by Indigenous Academic Librarians?}

For the most part, research or scholarship by Indigenous academic librarians would be considered similar to that of non-Indigenous librarians, with two main differences: one, the value of different types of research outputs (such as peer-reviewed articles, book chapters, edited books, books, conference presentations, or posters), and two, the concepts of subjectivity and objectivity in research. The main difference regarding the value of various types of research outputs would be that we (and our research participants) may not be so concerned with the peer-review process. Ultimately, we want practical results from doing the research, that is, results that will improve the situation or the self-determination of our people. For instance, research output in the form of a government or NGO report would be acceptable and highly valued by us and our communities, but may not be accepted as research or scholarship by the academy. This kind of publication might be considered a technical report by the academy and not as highly valued as, say, a peer-reviewed article. Yet the time and effort involved in conducting the research for and writing that government report could far outweigh other kinds of research outputs, including writing a thought piece such as this one. An Indigenous community member might value a technical report that serves to inform federal government policy that will, in turn, provide benefits to Indigenous communities far more than an academic, peerreviewed article; indeed, they might question the value of the latter altogether if it has no benefit to their community.

In addition, a qualitative library research project involving Indigenous peoples (and this is what I intend to focus on in this article, to limit its scope) often demands a lot of relationship-building along the way. We value research projects that involve participants we know and those that undertake long-term relationship-building practices. For instance, when I was working on my graduate studies research project where I interviewed six students at the university where I was studying about their use of academic libraries, five of the six interviewees were people I already knew, some of them for the previous seven or more years, since I was an undergraduate student (Lee, 200I). I was also a participant in one of these students' graduate research projects. Although this might be considered by some Western researchers to be a non-objective study (and, thus, lacking in validity), I was working with my on-campus 
community of Indigenous students and therefore the research results were highly valued by the participants, as long as I was being accountable to them. Respecting the work of Smith, I provided each participant with a copy of the published article, and they felt validated in that they had been heard.

Further, Indigenous researchers do not see conducting qualitative research as an objective exercise; rather, it must be subjective if you have the interest in doing it in the first place and if your primary interest is that the research results benefit the community. It is necessary to care about one's research in order to invest quality time and effort in it. While Western researchers also care about the research they do, their focus on objectivity in research means that they are unlikely to demonstrate this kind of passion for it.

One of the manifestations of the subjective nature of Indigenous scholars' research is the use of I-statements in our research outputs. Conversely, many Western scholars find this practice troubling. All four of the Indigenous researchers who published the books on Indigenous methodologies that I referenced earlier in this article have no qualms about their use of subjective I-statements. Jo-ann Archibald opens her first chapter with, "Early this morning I asked for guidance from the Creator" (2008, p. I). Not only is she opening with an I-statement, she is also opening with a prayer. Smith opens her introduction with, "From the standpoint of the colonized, a position from which I write and choose to privilege, the term 'research' is inextricably linked to European imperialism and colonialism" (I999, p. I). In Shawn Wilson's first chapter, he starts with, "This chapter introduces the overall questions I want to answer. I also present the academic rationale behind these questions" (2008, p. I2). He then begins to talk about relationality as a necessary component of doing research and, in the following paragraph, begins a letter to his three sons about his motivations for doing the research. Likewise, Margaret Kovach opens her introduction with a personal story about a time when she delivered a presentation about her research in a college setting (2009, p. 9). She had done so several times previously, but what was different about this session was that, at the end, a young Indigenous student cautiously made her way to talk to Dr. Kovach when most people in attendance had already left. This student asked about her right to use Indigenous methodologies when she had grown up in the city and had no connections to her Indigenous community. Dr. Kovach confides to the reader her emotional reaction to being asked this question and how she responded to the student. Her approach to introducing readers to her research was different from a typical Western approach that prides itself on lacking in emotion. However, the personal story she shared is both foundational to her approach to research and highly memorable for readers of her book. 
Knowing that Indigenous researchers are comfortable using subjective I-statements in their academic writing may help non-Indigenous librarians open their consciousness to other styles of academic writing. In the past, I have been critiqued for using the subjective "I" in my academic writing, but I hope this section will help others understand that subjectivity can be a powerful teaching tool.

In terms of how Indigenous research methods can intersect with academic library research, Indigenous librarians have asserted their ways of knowing, relational methods, and community protocols through their published works for some time now (see Littletree \& Metoyer, 2015; Garwood-Houng, 2005; Lawson, 2004). I have also used these methods on several occasions, including while conducting qualitative research during my (previously mentioned) graduate course work. Since graduating with my MLIS, I have had the opportunity to work with my community of Indigenous librarians from across Canada on a variety of research projects:

- a co-edited compilation of oral history essays by Indigenous and visible minority librarians (Lee \& Kumaran, 20I4)

- an edited compilation of essays by Indigenous and non-Indigenous members of the Library Services for Saskatchewan Aboriginal Peoples Inc. Committee to celebrate its 25-year anniversary (Lee, 2016)

- a sabbatical research project in which I interviewed 27 Indigenous librarians across the country. This project has, so far, resulted in a peer-reviewed article (Lee, 20I7), which provides some much-needed context about the reasons why there are so few Indigenous peoples who have chosen librarianship as a career.

I have every reason to believe that opportunities for using Indigenous research methods within qualitative research projects in a library context will continue into the future. For instance, I was recently invited to be an Indigenous Advisory Circle member of an Ithaka $\mathrm{S}+\mathrm{R}^{3}$ international study pertaining to improving library services for Indigenous Studies scholars from across Turtle Island (i.e., North America). I was nominated to be the person responsible for Indigenizing the research project guide, including the interview schedule, which encouraged a conversational and story-telling approach. Much of the content in the research guide informs the process for obtaining ethics review approval at each research site. There are five academic library research sites in Canada and another six in the United States. I was also the lead on the research project at the University of Saskatchewan, and I worked with a team of two non-Indigenous librarians to recruit participants, conduct the interviews, analyze and code the interview transcripts, and write the final report (now published, see Lee, Smith \& Gagné, 20I8). All of the academic library research teams involved in the Ithaka $S+R$ project have learned how to do qualitative research

3. Ithaka $\mathrm{S}+\mathrm{R}$ is a non-profit organization which conducts research in various areas of higher education, including academic libraries. It is based in New York City. 
from an Indigenous research methodologies perspective. Many of the researchers working on this project have been presenting their research findings at conferences in the last while. Some might also write articles for publication on this important research project. For those interested, Ithaka $S+R$ has published a capstone report that synthesizes and integrates content from the reports of all of the II research sites (Cooper, et al., 2019). Additionally, similar studies (where there are intersections between academic libraries and Indigenous peoples, such as on Indigenous students' use of libraries) could and likely will be undertaken in the future, and, again, should only be undertaken through an Indigenous research methodologies lens.

\section{Storytelling as a Research Methodology}

Storytelling by Indigenous peoples is a well-known and effective tradition for transmitting knowledge, particularly from one generation to another, although this is not always the case. This quote from Cherokee-Greek author Thomas King is often repeated: "The truth about stories is that's all we are" (King, 2003, p. 2). For many people, hearing a story, perhaps used by the storyteller as a way to illustrate a theory, concept, or protocol, is an effective way to more easily remember and understand that theory, concept, or protocol. Smith explains how storytelling is central to Indigenous peoples' epistemologies:

Story telling, oral histories, the perspectives of elders and women have become an integral part of all Indigenous research. Each individual story is powerful. ... These new stories contribute to a collective story in which every Indigenous person has a place.... The story and the story teller both serve to connect the past with the future, one generation with the other, the land with the people and the people with the story. (1999, pp. I44-I45)

The importance of story as methodology is evident in the work of Dr. Jo-ann Archibald, who spent many years working with Elders (mostly Sto:lo Elders) to learn to listen to, understand, and tell stories and make story meaning (an intuitive process of reflecting on stories told and heard that educates the heart, mind, body, and spirit). In her book Indigenous Storywork, she prioritizes the seven storywork principles: Respect, Responsibility, Reciprocity, Reverence, Holism, Interrelatedness, and Synergy. One way in which she discusses these principles is by quoting Sto:lo author Lee Maracle:

We regard words as coming from original being-a sacred spiritual being. The orator is coming from a place of prayer and as such attempts to be persuasive. Words are not objects to be wasted. They represent the accumulated knowledge, cultural values, the vision of an entire people or peoples.... [T] hus, story is the most persuasive and sensible way to present the accumulated thoughts and values of a people. (2008, p. 26)

She also quotes one of the Elders she worked with, Ellen White, about story as pedagogy: 
"Our lives are stories.... Storytellers have to be very responsible. They are setting the pace of breathing. A story is, and has, breath. Storytellers learn to let that happen." I

[Maracle] believe that Ellen is talking about the power of story to "be the teacher," which is a storywork pedagogy. (p. II2)

Stories as research methodology are highly encouraged by Indigenous scholars. Sharing stories not only generates reciprocal understandings, but also deepens relationships. We bond through storytelling, and it breaks down hierarchies and builds trust. Stories can be the glue that holds the research project together, or they can be the most rewarding part of conducting the research. Smith helps us understand the power of sharing stories:

Sharing is a good thing to do, it is a very human quality. To be able to share, to have something worth sharing gives dignity to the giver. To accept a gift and to reciprocate gives dignity to the receiver. To recreate something new through that process of sharing is to recreate the old, to reconnect relationships and to recreate our humanness. (1999, p. I05)

In the latest qualitative research project I conducted, the stories shared were what made all the difference. Indeed, the stories shared were what made the research the most worthwhile doing and not only bonded the researchers with the interviewees but also bonded the research team to each other. We all agreed that conducting this research project was the best part of our professional responsibilities over the last year. Despite the many challenges involved in doing this research (especially the heavy demands on our time), we considered this project a gift. It is vital that Indigenous researchers record stories shared by other Indigenous peoples, primarily because our voices have been ignored, erased, under-valued, and misinterpreted for so long. This is what motivates me to conduct research with Indigenous peoples; it is a way to reclaim our space, to counter past wrongs, and to give back to community.

Similarly, Dr. Kovach dedicates one chapter of her book to story as methodology. Stories are important because they generate a sense of belonging. Additionally,

[s]tories hold within them knowledges while simultaneously signifying relationships. ... [Stories] are active agents within a relational world, pivotal in gaining insight into a phenomenon. (2009, p. 94)

But story as Indigenous methodology is not to be confused with a lightweight or superficial understanding of our worldview:

Concurrently, the use of story as method without an understanding of cultural

epistemology, defined broadly, can create problems with understanding the totality of Indigenous narrative. Cultural specificity of Indigenous story is manifest in teaching and personal narratives and can have profound implications for the interpretation of story within research... The notion that everyone understands story and that it is an effective means for gaining insight and making sense of the world is not contested. What is contested is that story is an apolitical, acultural method that can be applied without 
consideration of the knowledge system that sustains it. From that perspective, engaging with tribal stories means understanding their form, purpose, and substance from a tribal perspective. To attempt to understand tribal stories from a Western perspective (or any other cultural perspective) is likely to miss the point, possibly causing harm. (ibid., p. 97)

Kovach is referring to potential issues of both appropriation of Indigenous voice and misrepresentation of Indigenous culture and worldview, as occurred "during the dark years of anthropological research on Indigenous culture" (ibid.).

Later in this chapter, Kovach discusses story as methodology, how the researcher has to establish trust with a participant before stories are shared.

In asking others to share stories, it is necessary to share our own, starting with selflocation... The researcher's self-location provides an opportunity for the research participant to situate and assess the researcher's motivations for the research. (p. 98)

She then elaborates that

the research participant must feel that the researcher is willing to listen to the story. By listening intently to one another, story as method elevates the research from an extractive exercise serving the fragmentation of knowledge to a holistic endeavour that situates research firmly within the nest of relationship. (pp. 98-99)

This attentive and mutual process of listening, sharing, and understanding, along with the trust embedded in the relationship, serves to change the in-depth and unstructured (or semi-structured) interview to a conversation-style interview; hence, the term conversations is a significant inclusion in the title of her book. Kovach calls her interviews with her participants (who are Indigenous professors) conversations.

She also shares that her personal journey while conducting her doctoral research became a part of her research and changed her as a person. In her epilogue, she tells of many unusual but related occurrences that provided guidance and direction, particularly when she was stalled, not knowing where to go next. She realized she needed to go back home, to Saskatchewan, to do her research and to face some unanswered personal questions at the same time. Her appreciation for the sacredness of doing Indigenous research is expressed as follows: "The gift of Indigenous research frameworks is that it allows our story to be a part of our research. Research stories teach us much, they give us much. They tell us who we are as researchers, as people" (ibid., p. I83).

\section{Accountability in Conducting Research with Indigenous Peoples}

Dr. Shawn Wilson has made his mark regarding research with Indigenous peoples through his doctoral research interviewing fellow Indigenous graduate students about how to do this type of research. One of the strengths of his research paradigm that is not as clearly articulated in others' research is his notion of relational 
accountability. In order to explore this concept more fully, it is necessary to introduce readers to how Wilson arrived at his paradigm and its four components.

Early in his paradigm formulations, Wilson realized that there are some epistemological differences between Western and Indigenous researchers, which are frequently explained by other Indigenous scholars, such as Mayan scholar Carlos Cordero, whom he quotes as follows:

Within the Western knowledge system there is a separation of those areas called science from those called art and religion. The [Indigenous] knowledge base on the other hand integrates those areas so that science is both religious and aesthetic. We find then an emphasis in the Western tradition of approaching knowledge through the use of the intellect. For Indigenous people, knowledge is also approached through the use of the senses and the intuition. (2008, p. 55, emphasis mine)

So, for Wilson, there is holism and sacredness in conducting research. Cultural knowledge is a key component to conducting research with Indigenous peoples, alongside empirical knowledge. This speaks to the many ways of knowing the world (what Wilson refers to as holism), including through our spirituality. Indigenous ways of knowing are also often seen through the lens of relationality. In Wilson's words, "All things are related and therefore important" (p. 58). For readers who are unfamiliar with the concept of accountability in relationships with Indigenous peoples, it is similar to living the laws of Respect, Reciprocity, and Being in Relationship. These will be discussed more fully below.

Wilson also quotes other scholars, such as Evelyn Steinhauer, who talks about the three Rs of doing Indigenous research: Respect, Reciprocity, and Relationality (which are often considered the basic "Laws of Life"). "Respect means you listen intently to others' ideas, that you do not insist that your idea prevails" (p. 58). By respecting all components of the research process, including respect for the participants, the researcher takes "responsibility to act with fidelity in relationship to what has been heard, observed, and learnt" (Wilson, quoting Judy Atkinson, p. 59). In this way, Indigenous knowledge is not misinterpreted. The ceremony part of doing research includes following the protocols (laws of life) and doing the "preparation that happens long before the event" (p. 6I). For Wilson, "It is the voice [sic] from our ancestors that tell us when it is right and when it is not. Indigenous research is a life changing ceremony" (ibid.).

He then shares the components of his version of an Indigenous research paradigm: ontology (way of being), epistemology (ways of knowing), axiology (the study of the kinds of things that are valuable), and methodology. It is the axiology piece that I will elaborate on, and for Wilson it is based on relational accountability. Thus, Wilson states that Western paradigms value certain concepts such as validity, 
right or wrong, "statistically significant," worthy or unworthy (p. 77). But these do not have value in his research paradigm; instead, what is more important is his definition of relational accountability, which he defines as: "fulfilling a role and obligations in the research relationship - that is, being accountable to your relations" (ibid.).

Later, Wilson discusses accountability to relationships in more depth, adding that it is about "not objectifying knowledge and people in the research process. . .. It means interpretation of the knowledge is respectful and must help to build relationships established through the research process" (p. 77). He also provides examples of what can happen when doing research and not being accountable to relationships, including incorrect language translation and misinterpretation of the knowledge shared. Ultimately, it is about maintaining and not breaching a trust that has been developed throughout the research relationship and acting in ways such that you do not dishonour your ancestors.

\section{The Importance of Adhering to Indigenous Protocols}

What are Indigenous protocols, and how do they affect research conducted with Indigenous peoples? This will vary from one research project to another. For instance, if the researcher is conducting research by interviewing Elders, it would be essential (in most cases) to offer tobacco to each such research participant, either at the time of the request to do the interview or at the time of the interview. The purpose of offering tobacco is to acknowledge and express thanks for the wisdom that the Elder is about to share. For interviews with Indigenous peoples who are not Elders, offering tobacco is often a good idea, but is sometimes not a good idea. Some Indigenous peoples either do not follow that tradition (in some cases, these people have been Christianized) or, for various reasons, are not comfortable with it.

However, a major protocol that is universal when conducting research with Indigenous peoples is to build and maintain good relationships throughout the research process. Deanna Reder, Associate Professor at Simon Fraser University, spoke to this protocol at a recent Indigenous Literary Studies Association conference, and I have permission from her (Reder, personal communication, June 15, 2018) to paraphrase part of her talk as follows:

Indigenous protocols are about personal connections. They are a call to be a good guest and to be a good relative. To be a good guest, acknowledgement of Territory is essential but in a way that is meaningful. Bring a gift-it is a gesture of respect. In doing research with Indigenous peoples, researchers need to consider their motives. Dr. Weber-Pilwax encourages the same sentiment: Check your heart. Understand why you are doing your research. This is not taught in most programs. Dr. Kovach advocates for good research relations and identifying one's purpose in doing the research. It takes self-awareness and honesty to do this. (Reder, 20I8) 
This is interesting food for thought. Based on my own experience at library school, and that of many other librarians I've spoken with about MLIS research methods courses, the concept of inquiring about our motivations for conducting a particular research project has been absent from the material taught in these courses. This situation may have changed slightly in very recent times, such as when the instructor of the MLIS research methods course is a member of a marginalized community. But, for those teaching LIS research methods courses without bringing attention to and exploring this concept, I would encourage them to begin a dialogue with their students to understand why a researcher is doing their research, especially when the research topic concerns Indigenous peoples (and, indeed, other marginalized groups). As Reder states, being a good guest involves some selfawareness and honesty as well as awareness of the community's protocols.

Reder also spoke to the intricacies of garnering consent from research participants on a continual basis, because this adheres to the protocol of relational accountability and being responsible to your research participants:

Literary (and other) scholars aren't often taught how to be a good guest or good relative. Why you are doing the research is worth questioning. When conducting research with Indigenous peoples, it's important to understand that consent by the participant is an ongoing state. If the researcher cannot accommodate this, maybe they are not the right person for the project. This can be a painful realization. (2018)

Dr. Reder understands this first hand, as per a personal story that she shared:

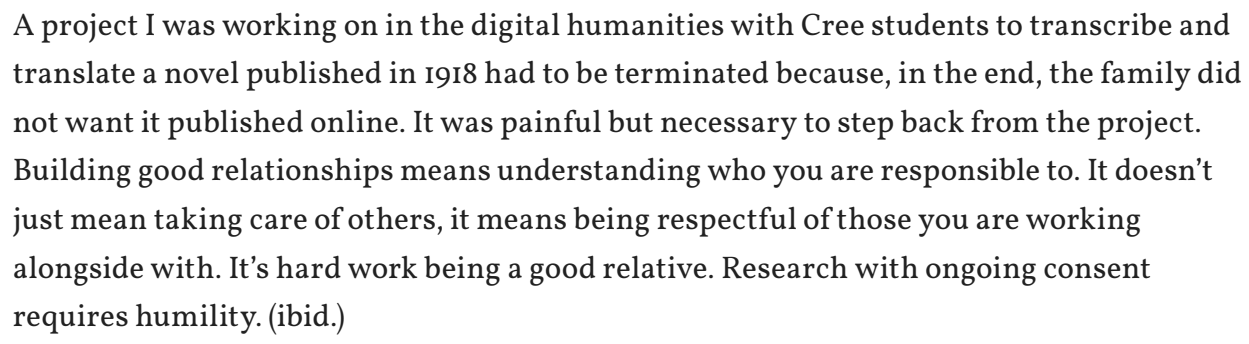

In other words, if a researcher is not prepared to adhere to Indigenous protocols or engage in a long-term, ongoing commitment with Indigenous peoples, then they should not undertake research with Indigenous peoples. This is all part of being accountable to the communities.

Further to Deanna's words on the protocol of gifting, it is common practice for the researcher to provide a gift to an Indigenous research participant, as a way to thank the participant for sharing their time with the researcher and to share one's generosity in conducting the research. Generosity is a respected Indigenous value, even if one has little to share. The dollar value of the gift is not important; it is the thought, and sometimes the sacrifice that had to be made to prepare the gift, that 
counts. I once attended a feast on a pueblo in New Mexico. We were invited into people's homes to share a meal with the families of each home on the pueblo that opened its doors to the visitors. In most cases, these families, who often live in poverty, saved up from the previous year in order to prepare these meals for the hundreds of visitors who came passing through, and they were honoured to do so. That is the depth of both their sacrifice and their honour in hosting the feast. To this day, I have offered a cultural gift (such as something beaded) to each person I have interviewed during the research process, gifts that have not been covered by any budget that might have been available for research projects I have worked on. While the gifts have not necessarily been lavish, they are a financial cost that I am honoured to incur.

Similarly, in cases where the research involves a large group of people meeting simultaneously, food is often offered as part of the research process. For instance, if the researcher is conducting focus groups or talking circles within Indigenous communities, a meal is generally provided for the research participants. The community often expects this type of gifting. It is always a good way to start a community event; it encourages visiting, helps with relationship-building, and provides space for engaging in other partnerships. In some cases, a researcher will ensure that there is more food available than there are people in attendance, so that Elders can take food home for children and grandchildren whom they may care for. Researchers should be prepared to share their many resources with community members. Sometimes there are giveaways at the end of a group research session; the giveaway items can include books (especially about the community's particular cultural group or nation), playing cards, socks, and dish towels.

One final protocol that I want to elaborate on is Reciprocity. This can take several forms, such as the researcher having the humility to understand that they don't know everything about conducting research with Indigenous peoples and being prepared and open to learn something about conducting this research from each participant they engage with. Kovach (2009, p. 122) cites Eber Hampton on acknowledging how research is, fundamentally, about learning. When a researcher accepts that both parties in the research will learn something from their research interactions, the researcher will benefit far more from conducting the research. The researcher may also realize that the research participant is also learning about the research process, for better or for worse, particularly if the research project does not go well.

Another way in which reciprocity can be manifested in the research process is for the researcher to be prepared that participants may request some access to resources that the researcher may have. For instance, a participant may request that the researcher write a grant application for the community, one that would help 
bring important benefits to the community but would otherwise be out of reach for them. In this way, participants may be acknowledging a need for the relationship between researcher and community to continue, thereby deepening the relationship between the two; it may also indicate that the participants are skilled in harnessing the resources of the researcher for the benefit of the community. The wise researcher will accept this invitation and carry out this request and feel honoured to do so. It is a recognition that the community members have deemed you worthy of continuing the relationship.

Chapter 9 of the TCPS 2 is also concerned with reciprocity when research involves Indigenous peoples. Article 9.I4 states, "Research projects should support capacity building through enhancement of the skills of community personnel in research methods, project management, and ethical review and oversight" (Panel on Research Ethics, 2014, p. 14).

\section{Special Considerations for Research Data Management}

Research data management encompasses many components, some of which are applicable to research involving Indigenous participants and some of which are not. For instance, data collected while conducting research with Indigenous community members is often expected (such as by research ethics boards at universities) to be stored in a safe place (i.e., on university servers) for five years after the research is completed and then destroyed. Many Indigenous communities and participants would have a problem with that and would expect the knowledge shared during the research process to exist in perpetuity. This is especially important in the case of interviews conducted in Indigenous languages (as has been done in the past, when more Indigenous peoples spoke their languages; sometimes these languages are now endangered and currently have very few speakers). Such interviews could serve Indigenous language preservation and revitalization purposes.

The TCPS 2, chapter 9, acknowledges that data storage can be quite different when Indigenous organizations and communities lead the research, as follows:

\footnotetext{
Many First Nations communities across Canada have adopted an ethics code originally developed to govern practice in the First Nations Regional Longitudinal Health Survey. The code asserts ownership of, control of, access to, and possession (OCAP) of research processes affecting participant communities, and the resulting data. OCAP addresses issues of privacy, intellectual property, data custody and secondary use of data. (Panel on Research Ethics, 20I4, p. Io, bold in the original)
}

Further, the First Nations Regional Longitudinal Health Survey (FNRLHS) has facilitated processes that assist Indigenous communities to hold and store their own data, usually through a regional organization designated by the communities. 
This organization will then evaluate requests for information; these evaluations of requests then influence decisions made by local authorities as to who will have access to the data and how (ibid., p. 15).

In addition, researchers conducting research with members of small First Nations communities must take into consideration additional safeguards to address the privacy concerns of these members. In communities where everyone knows everyone,

coding individual data is often not sufficient to mask identities, even when data are

aggregated.... Communities themselves have distinguishing characteristics, which in some cases have compromised efforts to disguise the research site, and has led to the stigmatization of entire communities. (ibid.)

TCPS 2, chapter 9 also notes that, in some circumstances, the nature of the information collected at the time of interviews can easily be associated with the identity of the participant who was interviewed. When this happens, the TCPS 2 recommends seeking the consent of attribution from such participants (ibid.).

Keeping these special considerations in mind, it would seem impractical, unethical, and contrary to the efforts that go into building trusting relationships with Indigenous participants and communities during the research process to provide this data to open repositories. In the recent research that I have done, every Indigenous participant opposed the idea of making their research data accessible to anyone outside of the research team. Clearly, more work needs to be done to reconcile what Indigenous researchers and participants want in terms of protecting the privacy of their community members with the Tri-Council's new draft policy requiring all of its funded research data (including in the social sciences and humanities, the jurisdiction of SSHRC, whereas previously, in prior versions, this requirement was applicable only to CIHR and NSERC funded projects) to be made available in open repositories. This new draft policy seems to leave some room for a data management plan (DMP) to indicate "legal, ethical or commercial constraints that the data are subject to" (Collaboration Between Federal Research Funding Organizations, Government of Canada, 20I8, as stated in Section 3.2 Data Management Plans, p. 3). A DMP for a research project in the social sciences and humanities conducted with Indigenous peoples could include a description of how detrimental it would be to the success of the research project if the research data were mandated to be deposited in an open repository. This is an important conversation that needs to be had and hashed out; fortunately, the Tri-Council Agencies asked for feedback from researchers on the new draft. My understanding is that many universities across the country responded to this request for feedback. We will see how this plays out with the final version of this document in the coming months. Discussing it briefly here is an important first 
step to broaden the conversation on research data management so that librarians are aware of the ethical complexities involved. Indigenous researchers (and hopefully others) would not want SSHRC, in the near future, to not fund a project involving Indigenous community members primarily because the researchers on the project do not see it as ethical to contribute their research data to an open repository. Another concern is that if Indigenous research participants were informed at the outset of the research process that their interview transcripts were required to be uploaded to an open repository, most potential participants would decline to be interviewed.

To add to the complexity of the suitability of open repositories for research data involving Indigenous peoples, some research partnerships with Indigenous communities are well placed to expand access to Indigenous materials in open repositories, such as those that use Mukurtu software. Mukurtu is free contentmanagement software that has been created for community-driven projects in order to empower Indigenous communities to digitally preserve and organize their own community's cultural heritage, such as archival photos and textual documents. Sometimes additional contemporary content, such as videos of interviews with Elders in the community, providing some important context for the archival photos, will be included. Mukurtu projects are, at times, open only to the community whose content is being preserved and sometimes the content (or part of the content) is open to all. An interesting example of such a project that is at least partially open to all is called the Plateau People's Web Portal, ${ }^{4}$ a project that is partially supported by Washington State University. It is important to remember that, for Mukurtu projects, it is the communities who make use of their agency and decide which documents are uploaded to the repository.

This is different from the situation with qualitative research that is typically funded by grants from SSHRC, where the research is usually not community-driven and the research participants have little agency over how the information they have shared will be used by others. This is not to say that SSHRC could not fund a Mukurtu-based project, but there would need to be two essential considerations. One, the focus would be on a different kind of research data content than what I referred to earlier in this section (i.e., primarily archival documents rather than contemporary qualitative interview data); and, two, if the archival document was a recording of private or sacred stories, these would not be eligible for uploading to a totally open repository. If SSHRC funded such a project and they expected all of the digitized content to be held in an open repository for access beyond the community, this would be problematic for both the researcher and the community.

4. HTtPS://PLATEAUPORTAL.LIBRARIES.WSU.EDU/ 


\section{Conclusion}

As shown through the discussion above, conducting qualitative research with Indigenous peoples and communities is very different from conducting qualitative research in the Western tradition. There is much to be thoughtful of and resolve in this kind of qualitative research journey, including the long history of exploitation by non-Indigenous researchers when conducting research with Indigenous peoples, the need to respect Indigenous protocols and develop trust, the relational epistemologies and methodologies that are foundational to the success of these research projects, and special considerations that need to be accommodated, such as in the area of research data management. As librarians concerned about responding "in a good way" to the TRC Calls to Action we need to be aware of and respectful of the issues involved with conducting research with Indigenous peoples so that we don't cause further harm (such as misrepresentation of Indigenous peoples, cultures, or values). Further, academic librarians need to be aware of the concerns of Indigenous scholars and researchers related to research data management so that we do not overstep boundaries in our zeal to fulfill our role in making research data available in open repositories.

In addition, all researchers and scholars, including academic librarians, need to "check our hearts" (recalling Cora Weber-Pilwax as quoted in Reder's conference presentation), examine our motivations for wanting to do this research. If librarians have not had much contact with Indigenous peoples prior to undertaking a research project with them, and do so without partnering with Indigenous researchers, then the project will likely fail. The best intentions are not enough to make it work, because a lack of understanding of the complexity of the issues will mean that those best intentions are not necessarily the best solutions for the community involved. It cannot be overstated that humility, reciprocity, accountability, and long-term commitment are critical values required when conducting research with Indigenous peoples and communities. Further, knowing about Indigenous research methodologies can provide another way for librarians to demonstrate their cultural competency skills when serving and supporting Indigenous Studies researchers and scholars.

\section{ABOUT THE AUTHOR}

Deborah Lee is a nēhiyaw (Plains Cree), Métis, and Kanienkehaka (Mohawk) librarian working at the University of Saskatchewan. Her research interests include Indigenous librarianship, Indigenous research methodologies, Indigenous health, Indigenous literatures, and Indigenous arts in all formats and genres. 
Battiste, M. (2015). Part of a panel presentation on "Setting a Change Agenda for University Research," at the first Building Reconciliation National Forum, University of Saskatchewan, November I8-I9, 2OI5. Retrieved from HTTPS://ABORIGINAL.USASK.CA/DOCUMENTS/UnivERSITY \% 20OF\%2O SASKATCHEWAN \% 2OBUILDING\%2ORECONCILIATION\%2ONATIONAL\%2OFORUM\%2OREPORT.PDF.

Battiste, M. \& Henderson, J. (S.) Y. (2000). Protecting Indigenous Knowledge and Heritage: A Global Challenge. Saskatoon: Purich Publishing.

Blair, N. (2015). Researched to Death: Indigenous Peoples Talkin' Up Our Experiences of Research. International Review of Qualitative Research, 8(4), 463-478. HT T P://DOI.ORG/IO.I525/ IRQR.2OI5.8.4.463.

Bone, C. \& Lougheed, B. (20I8). Library of Congress Subject Headings Related to Indigenous Peoples: Changing LCSH for Use in a Canadian Archival Context. Cataloging \& Classification Quarterly, 56(I), $83-95$.

Burns, K., Doyle, A., Joseph, G., \& Krebs, A. (2009). Indigenous Librarianship. In M. Bates and M. N. Maack (Eds.), Encyclopedia of Library and Information Sciences (3rd ed., vol. 3, 2330-2346). Boca Raton: Taylor \& Francis.

Canadian Association of Professional Academic Librarians, Revitt, E., Magnus, E., Schrader, A., and Wright, J. (2019). 2018 Census of Canadian Academic Librarians: User Guide and Results Summary. Toronto: The Association. Retrieved from HTtPS://CAPALIBRARIANS.ORG/WP/WP-CONTENT/ UPLOADS/2OI9/O3/2OI _ CENSUS _ MARCH _ 24 _ 2OI9.PDF.

Collaboration Between Federal Research Funding Organizations, Government of Canada (20I8). DRAFT Tri-Agency Research Data Management Policy-For Consultation. Ottawa: The Collaboration. Retrieved from HTtp://WWW.SCiEnCE.GC.CA/EIC/Site/O63.NSF/ENG/H_976IO.HTML.

Cooper, D., Ball, T., Boyer-Kelly, N. B., Carr-Wiggin, A., Cornelius, C., et al. (2019). When Research is Relational: Supporting the Research Practices of Indigenous Studies Scholars. New York: Ithaka S+R. Retrieved from HTTPS://DOI.ORG/IO.I8665/SR.3II240.

Farnel, S., Koufogiannakis, D., Laroque, S., Bigelow, I., Carr-Wiggin, A., Feisst, D., \& Lar-Son, K. (20I8). Rethinking Representation: Indigenous Peoples and Contexts at the University of Alberta Libraries. International Journal of Information, Diversity, \& Inclusion, 2(3), 9-24. HT T P S://D OI.ORG/IO.33 I 37/IJIDI. v213.32190.

First Nations Information Governance Centre. (20I4). Ownership, Control, Access and Possession (OCAP $\left.{ }^{T M}\right)$ : The Path to First Nations Information Governance. Ottawa: The Centre. Retrieved from H T T P ://F NIGC.CA/ SITES/DEFAULT/FILES/DOCS/OCAP_PATH _ TO _ FN _ INFORMATION _ GOVERNANCE_ EN _ FINAL.PDF.

Garwood-Houng, A. (2005). Protocols: Meeting the Challenges of Indigenous Information Needs. Australian Academic and Research Libraries, 36(2), I49-I57. HT TPS://DOI.ORG/IO.IO80/00048623.2005. IO72I 254 .

Goodman, A., Morgan, R., Kuehlke, R., Kastor, S., Fleming, K., Boyd, J., \& the Western Aboriginal Harm Reduction Society (20I8). 'We've Been Researched to Death': Exploring the Research Experiences of Urban Indigenous Peoples in Vancouver, Canada. International Indigenous Policy Journal, 9(2). н т т P s:// DOI.ORG/IO.I8584/IIPJ.2OI8.9.2.3.

King, T. (2003). The Truth about Stories: A Native Narrative. Toronto: House of Anansi.

Kovach, M. (2009). Indigenous Methodologies: Characteristics, Conversations and Contexts. Toronto: University of Toronto Press.

Lawson, K. L. (2004). Precious Fragments: First Nations Materials in Archives, Libraries and Museums (Master's thesis). Retrieved from https://open.Library.ubc.CA/CirCle/COLlections/ubCtheses/83i/ ITEMS/I.0091657.

Lee, D. A. (200I). Aboriginal Students in Canada: A Case Study of Their Academic Information Needs and Library Use. Journal of Library Administration, 33(3-4), 259-292. H T T P S://DOI.ORG/IO.I $300 /$ JIIIV33NO3 _ 07 . 
(2016). The Library Services for Saskatchewan Aboriginal Peoples' Inc. Committee: Celebrating 25 Years, I99I-20I6. Saskatoon: University of Saskatchewan.

(20I7). Indigenous Librarians: Knowledge Keepers in the 2Ist Century. Canadian Journal of Native Studies, 37(I), I75-I99.

Lee, D., \& Kumaran, M. (Eds.) (20I4). Aboriginal and Visible Minority Librarians: Oral Histories from Canada. Lanham, MD: Rowman \& Littlefield.

Lee, D., Smith, D. A., and Gagné, M.-L. (2018). University Library Report on the Ithaka S+R Study on Improving Library Resources and Services for Indigenous Studies Scholars: University of Saskatchewan Context. Saskatoon: University of Saskatchewan. Retrieved from HTTPS://HARVEST.USASK.CA/HANDLE/IO388/II626.

Littletree, S. \& Metoyer, C. A. (2015). Knowledge Organization from an Indigenous Perspective: The Mashantucket Pequot Thesaurus of American Indian Terminology Project. Cataloging \& Classification Quarterly, 53(5-6),640-657.HTTPs://DOI.ORG/IO.IO80/OI639374.20I5.IOIOII3.

Mi'kmaw Ethics Watch, Cape Breton University. (1999). Retrieved from HTtps://www.CBU.CA/ INDIGENOUS-AFFAIRS/UNAMAKI-COLLEGE/MIKMAQ-ETHICS-WATCH/.

Panel on Research Ethics. Government of Canada. (20I4). TCPS 2: Tri-Council Policy Statement (2nd Edition): Ethical Conduct for Research Involving Humans. Chapters I and 9. Last modified October I2, 2017. Retrieved from HTtp://WWW.PRE.ETHics.GC.CA/EnG/POLICY-POLITIQUE/INITIATIVES/TCPS2-EPTC2/ Default/.

Reder, D. (2018, May). Indigenous Protocols, part of a panel presentation on The People and the Text: Indigenous Writing in Northern North America until 1992. Indigenous Literary Studies Association Annual Conference, Congress of the Humanities and Social Sciences, First Nations University of Canada / University of Regina, Regina, SK.

Smith, L. T. (1999). Decolonizing Methodologies: Research and Indigenous Peoples. New York: Zed Books.

Wilson, S. (2008). Research is Ceremony: Indigenous Research Methods. Winnipeg: Fernwood. 